\title{
Glad tidings for haemophilia B patients
}

\section{Paul Giangrande}

Yuletide does indeed seem to be a time of year which heralds good tidings for patients with haemophilia $\mathrm{B}$. This disorder is still known as Christmas disease in much of the English-speaking world since the first case report from Oxford, which appeared in the British Medical Journal on 27 December 1952 [1]. Unusual results in the thromboplastin generation test indicated that the subject in question had a bleeding disorder that was quite distinct from classical haemophilia. Many readers assumed that the proposed eponym of Christmas disease reflected the publication date and several subsequent letters to the journal fulminated at the frivolity of using a Christian festival to describe a disease and demanded an apology. In fact, the name was derived from the surname of the boy: Stephen Christmas (his parents evidently had a sense of humour as his unaffected brother was named Robin). Nevertheless, the authors of the paper happily accepted the compromise suggested by Alexander Wiener, the distinguished serologist, to call this condition haemophilia B in order to avoid any further controversy.

Genetic studies published in 2009 on the remains of members of Russian Imperial family showed conclusively that the Tsarevich Alexei had haemophilia B [2]. The condition therefore acquired a second soubriquet of "Royal haemophilia", in recognition of the fact that Queen Victoria's affected descendants as well as those in the noble families of Russia, Spain and Germany had inherited the same genetic defect in exon 4 of the F9 gene. Many patients with haemophilia $B$ seem to take pride in this regal association. I have even heard some claim that a disproportionate number of patients with haemophilia B reach the highest pinnacles of office within our international community!

In some ways, patients with haemophilia B are indeed more fortunate. The original observation made by physicians in the 1950s that the bleeding tendency in haemophilia B is generally less severe than in haemophilia A seems to have borne out over the years $[3,4]$. The halflife of factor IX is longer than that of factor VIII, so less frequent infusions are required for prophylaxis. Far fewer patients with haemophilia B develop inhibitory antibodies. A small proportion with the Leyden phenotype will even be cured of their condition as the factor IX levels rise to within the normal level after puberty: no similar phenomenon has ever been described in haemophilia A [5]. However, it is equally true that that this small but distinguished group of patients has had to put up with second-class treatment for years. Both cryoprecipitate in 1968 and desmopressin

Dr Paul Giangrande, Oxford Haemophilia \& Thrombosis Centre, Oxford University Hospitals NHS Trust, OX3 7LE (UK) paul.giangrandeandm.ox.ac.uk

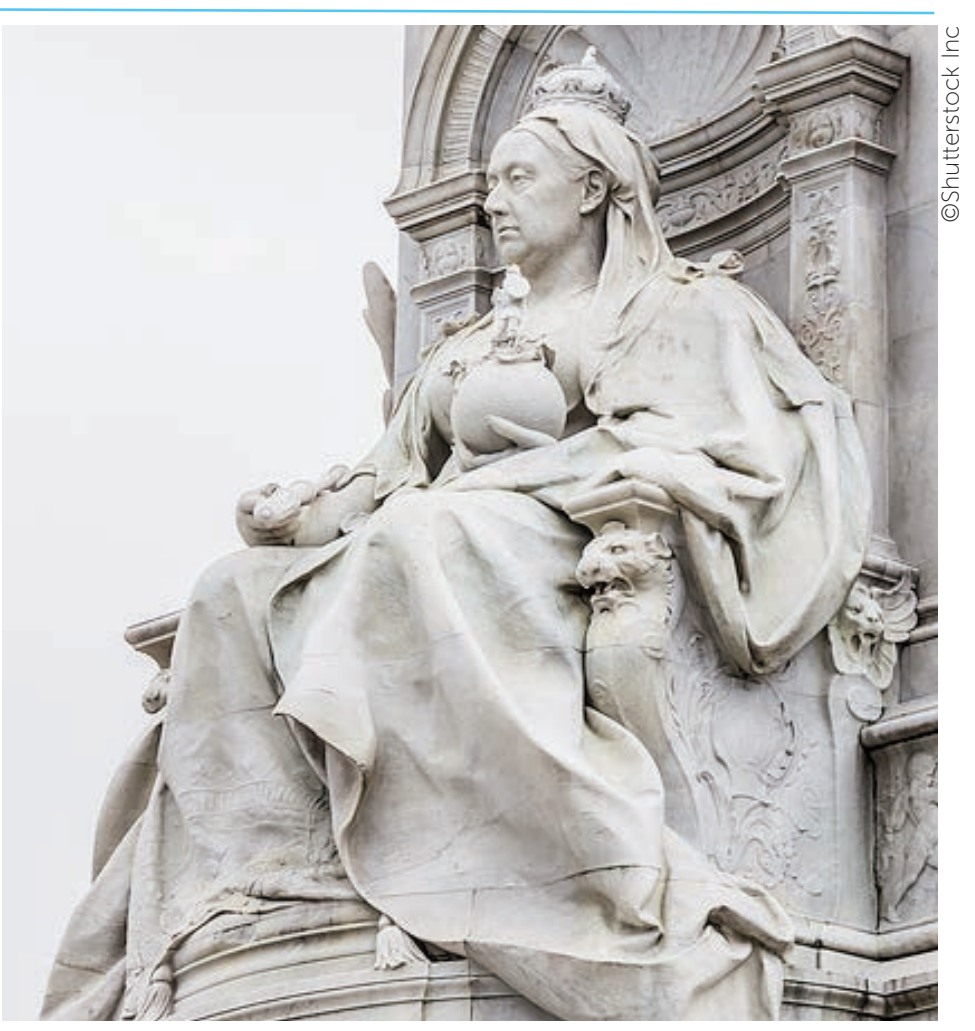

Queen Victoria was a carrier of haemophilia B: one son had haemophilia B and two daughters passed the gene on to boys in the Spanish and Russian royal families

(DDAVP) in 1977 transformed prospects for patients with haemophilia $A$, but neither product is of any value in haemophilia B.

There has always been a lag in the development of factor IX concentrates, both plasma-derived and recombinant. The very first plasma-derived concentrates manufactured in the 1950s were actually of porcine factor VIII (used for all patients with haemophilia in the early years, and not just those with inhibitors). The first factor IX concentrates were impure prothrombin complex concentrates and it soon became apparent that there was a risk of thromboembolism associated with their use. Pure single factor IX concentrates only became available several years after the equivalent products for haemophilia A. Similarly, recombinant factor IX was licensed in 1997, three years after factor VIII and it remains the case that there is just one brand of recombinant factor IX available. This monopoly results in higher prices which hinders access to therapy in some countries.

Now, the tables seem to be turning. Accompanied by a leader entitled "Merry Christmas for patients with haemophilia B", the New England Journal of Medicine trumpeted the results of the first successful gene therapy trial for haemophilia B in the edition of 22 December 2011 [6]. 
These results have now been updated in the same journal [7]. A single intravenous infusion of vector in ten patients with severe haemophilia $B$ resulted in a dose-dependent increase in circulating factor IX to a level that was 1 to $6 \%$ of the normal value over a median period of 3.2 years. Gene therapy in haemophilia $A$ is proving to be more challenging, as the much larger factor VIII gene is hard to squeeze into conventional viral vectors. There is now also the prospect of transgenic factor IX derived from pigs, which could result in production of large quantities at a cheap price.

A recent veritable blizzard of publications relating to longer-acting concentrates has highlighted a dramatic contrast. PEGylation and fusion with albumin or immunoglobulins are the three principal methods which have been used to extend the duration of action of coagulation factor proteins. The results obtained in the various clinical studies have been remarkably similar. With all three methods, it is possible to extend the half-life of factor IX fivefold. By contrast, it has so far only been possible to extend the half-life of factor VIII by around 1.5 fold. The results of one clinical trial indicate that a factor IX trough level of around $27 \%$ can be achieved with just one dose of $40 \mathrm{lU} / \mathrm{kg}$ each week [8]. There is now a clear consensus that the new longer-acting factor IX products are likely to transform the lives of patients with haemophilia B. Optimism about the equivalent factor VIII products is much more muted.

Finally, it is just possible that liver transplants may prove to be a cure for haemophilia A and B. At the moment, this is only carried out in cases of liver failure or cancer but this major surgery has the added bonus of curing haemophilia as the liver is the site of synthesis of both coagulation factors. This type of surgery is not to be undertaken lightly and the high risk of recurrence of underlying hepatitis and the risks associated with long-term immunosuppression are further barriers. Nevertheless, if these formidable obstacles can be overcome, even partial replacement could offer a real prospect of a definitive cure. Now, the hope that a fresh new liver could cure haemophilia is surely something to raise a glass of something alcoholic to at this time of year!

\section{References}

1. Biggs R, Douglas AS, Macfarlane RC, Dacie JV, Pitney WR, Merskey C, O'Brien JR. Christmas Disease. BMJ 1952; 2: 1378. doi

http://dx.doi.org/10.1136/bmj.2.4799.1378

2. Rogaev El, Grigorenko AP, Faskhutdinova G, Kittler EL, Moliaka YK. Genotype Analysis Identifies the Cause of the "Royal Disease". Science 2009: 326; 817. doi: 10.1126/science.1180660.

3. Quick AJ, Hussey CV. Hemophilia B (PTC deficiency, or Christmas disease). Arch Intern Med 1959; 103: 762-75. doi:10.1001/archinte.1959.00270050084014. 4. Mannucci PM, Franchini M. Is haemophilia B less severe than haemophilia A? Haemophilia 2013; 19: 499-502. doi: 10.1111/hae.12133.

5. Reijnen MJ, Sladek FM, Bertina RM, Reitsma PH. Disruption of a binding site for hepatocyte nuclear factor 4 results in hemophilia B Leyden. Proc Natl Acad Sci USA. 1992; 89: 6300-3

6. Nathwani AC, Tuddenham EG, Rangarajan S, et al. Adenovirus-associated virus vector-mediated gene transfer in hemophilia B. N Engl J Med 2011; 365: 2357-65. doi: 10.1056/NEJMoa1108046.

7. Nathwani AC, Reiss UM, Tuddenham EG, Rosales C, Chowdary P, Mclntosh J, et al. Long-term safety and efficacy of factor IX gene therapy in hemophilia B. N Engl J Med 2014; 371: 1994-2004. doi: 10.1056/NEJMoa1407309.

8. Collins PW, Young G, Knobe K, et al. Recombinant long-acting glycoPEGylated factor IX in hemophilia B: a multinational randomized phase 3 trial. Blood First Edition Paper, prepublished online September 26, 2014; DOI 10.1182/blood-2014$05-573055$

\section{The Journal of Haemophilia Practice} An open-access journal for sharing experience in the care of people with bleeding disorders

\section{www.haemjournal.com}

